\title{
Design and Testing of a Shell-Flow Hollow-Fiber Venting Gas Trap
}

\author{
Grant C. Bue, ${ }^{1}$ Cindy Cross, ${ }^{2}$ and Scott Hansen $^{3}$ \\ NASA Johnson Space Center, Houston, Texas, 77058 \\ and \\ Matthew Vogel ${ }^{4}$ and Paul Dillon ${ }^{5}$ \\ Jacobs Engineering, Engineering and Science Contract Group, Houston, Texas, 77058
}

\begin{abstract}
A Venting Gas Trap (VGT) was designed, built, and tested at NASA Johnson Space Center to eliminate dissolved and free gas from the circulating coolant loop of the Orion Environmental Control Life Support System. The VGT was downselected from two different designs. The VGT has robust operation, and easily met all the Orion requirements, especially size and weight. The VGT has a novel design with the gas trap made of a five-layer spiral wrap of porous hydrophobic hollow fibers that form a cylindrically shaped curtain terminated by a dome-shaped distal plug. Circulating coolant flows into the center of the cylindrical curtain and flows between the hollow fibers, around the distal plug, and exits the VGT outlet. Free gas is forced by the coolant flow to the distal plug and brought into contact with hollow fibers. The proximal ends of the hollow fibers terminate in a venting chamber that allows for rapid venting of the free gas inclusion, but passively limits the external venting from the venting chamber through two small holes in the event of a long-duration decompression of the cabin. The VGT performance specifications were verified in a wide range of flow rates, bubble sizes, and inclusion volumes. Long-duration and integrated Orion human tests of the VGT are also planned for the coming year.
\end{abstract}

\section{Nomenclature}

$\begin{array}{ll}\text { ECLSS } & =\text { Environmental Control Life Support System } \\ \text { ISS } & =\text { International Space Station } \\ \text { JSC } & =\text { Johnson Space Center } \\ \text { LCG } & =\text { Liquid Cooling Garment } \\ M P C V & =\text { Multi-Purpose Crew Vehicle } \\ P I S T & =\text { Pressure Integrated Suit Test } \\ \text { SWME } & =\text { Suit Water Membrane Evaporator } \\ V G T & =\text { Venting Gas Trap } \\ v P I S T & =\text { variable Pressure Integrated Suit Test }\end{array}$

\section{Introduction}

$\mathrm{T}$ The Multi-Purpose Crew Vehicle (MPCV) gas trap is part of the pump package in the MPCV Liquid Cooling Garment (LCG) loop. The gas trap is located upstream of the pump to remove free gas from the cooling water during loop operation to prevent de-priming of the pump and loss of coolant flow. There are a few possible sources for free gas introduction to the LCG loop. In preparation for suited operations, connectors within the suit and the umbilicals that interface to the vehicle are mated. During mating, gas can be trapped between the mating surfaces

\footnotetext{
${ }^{1}$ Aerospace Technologist, 2101 NASA Parkway, Houston, TX, 77058, Mail Stop EC2, nonmember

${ }^{2}$ Aerospace Technologist, 2101 NASA Parkway, Houston, TX, 77058, Mail Stop EC2, nonmember

${ }^{3}$ Aerospace Technologist, 2101 NASA Parkway, Houston, TX, 77058, Mail Stop EC2, nonmember

4 Thermal Analyst, 2224 Bay Area Blvd., Houston, TX, 77058, Mail Stop JE-5EA, member

5 Thermal Analyst, 2224 Bay Area Blvd., Houston, TX, 77058, Mail Stop JE-5EA, member
} 
and introduced into the LCG loop. Also, permeation of gas through the tube walls of the soft goods leads to accumulation of gas in the LCG loop. A third significant source is in the event of a cabin depress event causing dissolved gas in equilibrium with the normal cabin pressure to instantaneously come out of solution as the cabin pressure drops.

Small amounts of free gas are tolerable in the system and will not cause de-priming; however, over time, if allowed to circulate, these small amounts of free gas may significantly affect the life of the pump. This circulating gas does affect the stability of the output and the efficiency of the LCG heat transfer. Therefore, with subsequent passes, it is important for the gas trap to eliminate even trace amounts of free gas.

NASA initially considered a non-venting design concept that would have met all the requirements. ${ }^{1}$ Existing commercial membrane technology for degassing suggests that system requirements could be met with smaller mass and volume with a venting technology. ${ }^{2}$ One such module, which used a shell-flow design, was modified and recently ground tested for the International Space Station (ISS) Environmental Control Life Support System (ECLSS) coolant loop. ${ }^{3}$ Custom designs for Suit Water Membrane Evaporator (SWME) also showed excellent degassing characteristics with a tube-flow design, typical of their commercial counterparts. ${ }^{4-7}$ Accordingly, a development project was undertaken to design, build, and test a venting gas trap specifically tailored for Orion's requirements that significantly reduce the size and volume compared with non-venting designs. Two shell-flow and one tube-flow design concepts were compared. A tube-flow concept that meets all the Orion requirements was built and tested.

\section{Requirements}

The current requirements assume that the Venting Gas Trap (VGT) will be physically located within the pressurized MPCV cabin, behind a control panel. Therefore, the VGT eventually will be designed to withstand launch and landing loads, but not kick loads. Additionally, any biocide-related requirement related to the LCG cooling loop is not included in VGT requirement. These and possibly other requirements will be included in future designs after this proof-of-concept article has been manufactured and tested.

- Bubble Removal: 99 percent (by volume) of a 16 cc non-condensed gas (bubble) from a cooling water line, which has a flow rate of $298 \mathrm{~kg} / \mathrm{hr}(656 \mathrm{lbm} / \mathrm{hr})$, in 5 minutes.

- $\quad$ Single-Pass Bubble Removal: 98 percent (by volume) of a 16 cc non-condensed gas (bubble) from a cooling water line, which has a flow rate of $298 \mathrm{~kg} / \mathrm{hr}(656 \mathrm{lbm} / \mathrm{hr})$, in a single pass.

- $\quad$ Maximum Volume: $2556 \mathrm{~cm}^{3}\left(156 \mathrm{in}^{3}\right)$ or less.

- Maximum Mass: $3.18 \mathrm{~kg}(7.02 \mathrm{lbm})$ or less.

- $\quad$ Maximum Pressure Drop: $6.87 \mathrm{kPa}(1 \mathrm{psi})$ at $298 \mathrm{~kg} / \mathrm{hr}(656 \mathrm{lbm} / \mathrm{hr})$.

- $\quad$ Maximum Flow Rate: 298 kg/hr (656 lbm/hr).

- $\quad$ Maximum Design Pressure: maximum cooling fluid pressure of $240 \mathrm{kPa}(35.0 \mathrm{psi})$.

- $\quad$ Proof Pressure: $360 \mathrm{kPa}(52.5 \mathrm{psi})$.

- $\quad$ Burst Pressure: $600 \mathrm{kPa}(87.5$ psi).

- Vacuum Compatibility: operate in a vacuum environment for up to 144 hours.

- Water Loss: less than $1.59 \mathrm{~kg}(3.5 \mathrm{lbm})$ over a 21-day mission with a unpressurized cabin for the last 144 hours.

- $\quad$ Fluid Temperature Range: $8.3^{\circ} \mathrm{C}\left(47^{\circ} \mathrm{F}\right)$ to $27^{\circ} \mathrm{C}\left(80^{\circ} \mathrm{F}\right)$.

- $\quad$ Environmental Temperature Range: $18^{\circ} \mathrm{C}\left(64.4^{\circ} \mathrm{F}\right)$ to $27^{\circ} \mathrm{C}\left(80^{\circ} \mathrm{F}\right)$.

- Cycle Life: 308 umbilical mate/demates, and at least 21 continuous days of operation.

The cycle life assumes a crew of four each conducting umbilical mate or de-mate operations at the same time. This results in a free gas introduction of $16 \mathrm{cc}$ for each operation assumed to be done in unison by the crew a total of 77 times in the pressurized phase of the mission (four crew *77 $=308$ umbilical cycles).

\section{Venting Gas Trap Designs and Downselect}

\section{A. Tube-Flow Venting Gas Trap}

Error! Reference source not found. presents a Tube-Flow VGT design based on SWME architecture. Coolant water flows into the inlet header and into the hollow fibers and out the outlet header. Gas bubbles enter the tubes vent through the hollow fiber micropores into the shell-side free volume bounded by the external housing. The gas bubble vents through two 330-micron (0.013-inch) diameter holes. The two holes provide for complete venting of the gas bubble from the free volume space within 1.7 seconds while limiting the water loss over the 144-hour cabin 
depressurization event to less than $1.05 \mathrm{lbm}$, together with the loss of water vapor by diffusion against the ambient pressure during the first 15 days of operation easily meets the water loss requirement.
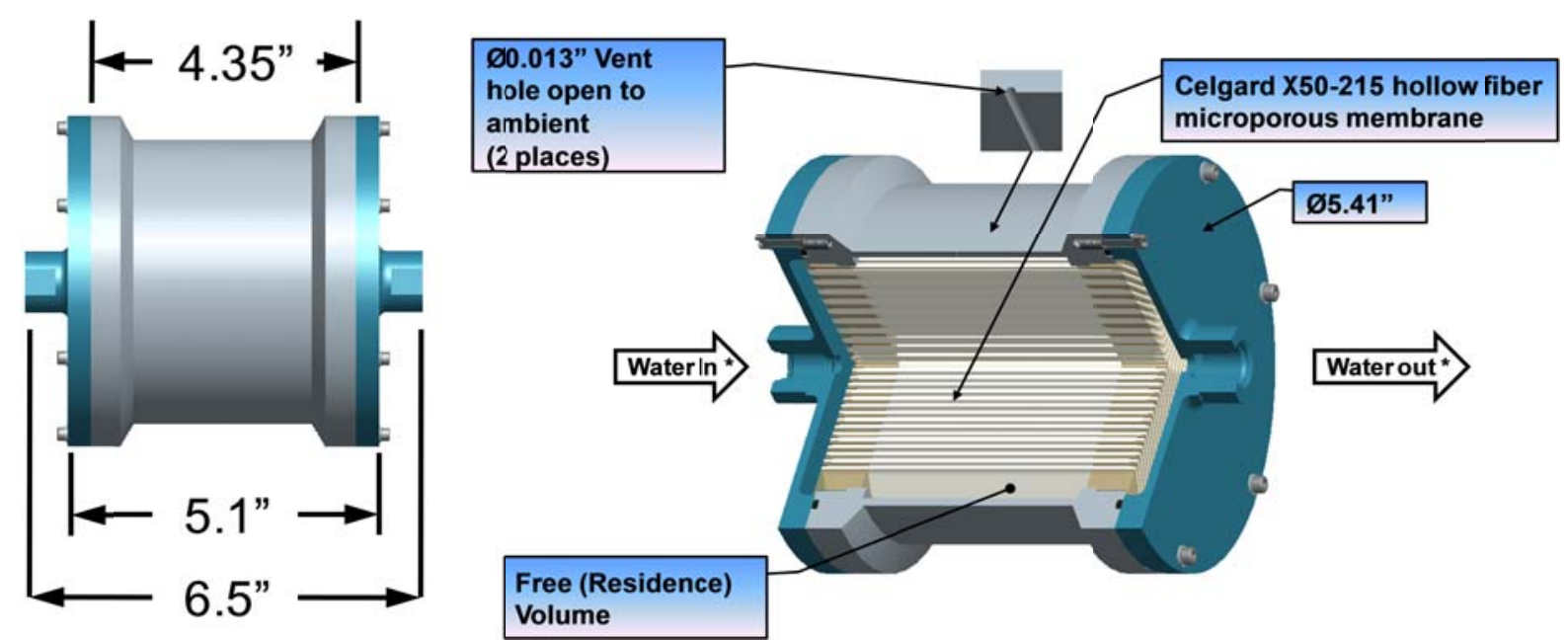

Figure 1. Tube-flow VGT design.

The difficulty with this design is that to just meet the pressure drop requirement, the number of fibers was doubled from that of SWME, while the active length was reduce to about one half. The resulting size of the TubeFlow VGT is $2447 \mathrm{~cm}^{3}\left(149.4 \mathrm{in}^{3}\right)$, just under the volume requirement of $2556 \mathrm{~cm}^{3}\left(156 \mathrm{in}^{3}\right)$. This would likely be larger than the non-venting prototype. To meet a pressure drop goal of $60 \%$ of the requirement, the volume envelope would be $3288 \mathrm{~cm}^{3}\left(200.7 \mathrm{in}^{3}\right)$, which exceeds the volume requirement.

\section{B. Shell-Flow Venting Gas Trap}

A Shell-Flow VGT design is presented in Figure 2. Coolant water flows into the inlet header and into the core of the gas trap, which is surrounded by a cylindrical curtain made of a five-layer sheet of hollow fibers. The water flows axially toward the outlet and radially outward between the tubes of the hollow fiber sheet. Finally, the water flows around the end cap dome (purple) and exits through the outlet. Gas bubbles flow into the core space and are swept into the end cap dome and radially outward into the cylindrical curtain of hollow fibers where, due to the hydrophobic nature of the polypropylene tubes, the gas displaces the water. The position of the gas trap in the pumped loop results in a pressure gradient of about 8 psid between the outside and inside of the hollow fibers that drives the gas into the tubes. The gas flows into the $63.4 \mathrm{~cm} 3$ air volume ante-chamber (pink) and exits through two 330-micron (0.013-inch) diameter holes. The two holes provide for complete venting of the gas bubble from the ante-chamber while, as in the Tube-Flow VGT, limiting the water loss over the 144-hour cabin depressurization event to less than $1.05 \mathrm{lbm}$, thereby easily meeting the overall water loss requirement. The device is $19 \mathrm{~cm}$ (7.5 in) in length by $7.6 \mathrm{~cm}$ (3.0 in) in diameter, resulting in a $869 \mathrm{~cm}^{3}\left(53 \mathrm{in}^{3}\right)$ - about 34\% of the maximum volume envelope requirement. At the maximum flow rate, the predicted pressure drop across the fiber walls is $0.3 \mathrm{kPa}$, suggesting that the overall pressure drop of the system will be well below the maximum pressure drop.

Some preliminary bench scale tests were done with 2-layer, 4-layer, and 8-layer hollow fiber bands potted into channel stock. With cross flow provided at about $100 \mathrm{~kg} / \mathrm{hr}$ with a delta pressure $69 \mathrm{kPa}, 16$ cc injections of bubbles were completely trapped and vented from the system in less than 5 minutes. The Shell-Flow VGT was selected for the test article, based on these preliminary test results and the volume and pressure drop characteristics of the design, and is hereafter referred to as the VGT.

Parts were made for four identical prototypes that were potted and assembled. Each VGT has a mass of $0.36 \mathrm{~kg}$ $(0.79 \mathrm{lbm})$ when empty and about $0.68 \mathrm{~kg}(1.5 \mathrm{lbm})$ when filled with water - about $22 \%$ of the maximum mass requirement. 


\section{Test Methods}

The bubble removal, single-pass removal, pressure drop, proof pressure, vacuum compatibility, water loss, fluid temperature range and cycle life requirements detailed in Section II, were verified in test. For this purpose, a test stand was built on the Active Thermal Control System test platform in Building 7B at NASA Johnson Space Center (JSC) (Fig. 3). The VGT was installed in a glass bell jar vacuum chamber (Chamber V). Water flow was controlled up to the maximum flow rate of $298 \mathrm{~kg} / \mathrm{hr}(656 \mathrm{lbm} / \mathrm{hr})$ with a March Manufacturing positive displacement pump and monitored with a Micromotion F-Series high performance coriolis flow meter, and has an accuracy of $0.2 \%$ of the measured value. An Affinity chiller cart was used to maintain fluid temperature of the circulating loop through an intermediate stainless steel heat exchanger. Delta pressure measurements were taken between the inlet and outlet of the test article and were monitored continuously during the life cycle test using a Stellar Technology Pressure Transducer (Model 1500). Delta pressure measurements were verified with a pitot tube measurement of water column height on the inlet and outlet of the VGT with several flow rates up to and including the maximum flow rate. Gas injections were accomplished with a $20 \mathrm{~mL}$ syringe through a Luer lock connector and a three-way valve. Each of a series of 77 air bubble injections were $24 \mathrm{~mL}$ at the ambient pressure side so that at the higher pressure of the VGT the injection volume would be $16 \mathrm{~mL}$. During the first 15 days of test, the ambient pressure days, injections were conducted 3 to 4 times a day. Bubbles traveling through the VGT 
were monitored using a 3.3 MegaPixel Sony HD Handycam with 42x extended zoom capability. During the last 6 days of the life cycle test, the glass bell jar was lowered over the test article and exposed to vacuum ( $10^{\wedge}-4$ torr) obtained by using a Welch-ILMVAC scroll pump. Chamber pressure was monitored during this period by a Baratron 690A $100 \mathrm{mmHg}$ series, which has a worst-case accuracy of $0.12 \%$ of reading. Gas bubbles not collected in the gas trap were collected and measured through the use of a T-joint and graduated cylinder located immediately after the test article.. Located further downstream is a bellows and sight glass positioned vertically to allow the same water level to be maintained in each device. These devices were used to measure the mass of water within the test article through visual examination, thereby eliminating the use of a scale and associated creep during the 21-day test. In the event of an emergency, the test article can be isolated through the use of a three-way valve located immediately after the pump.

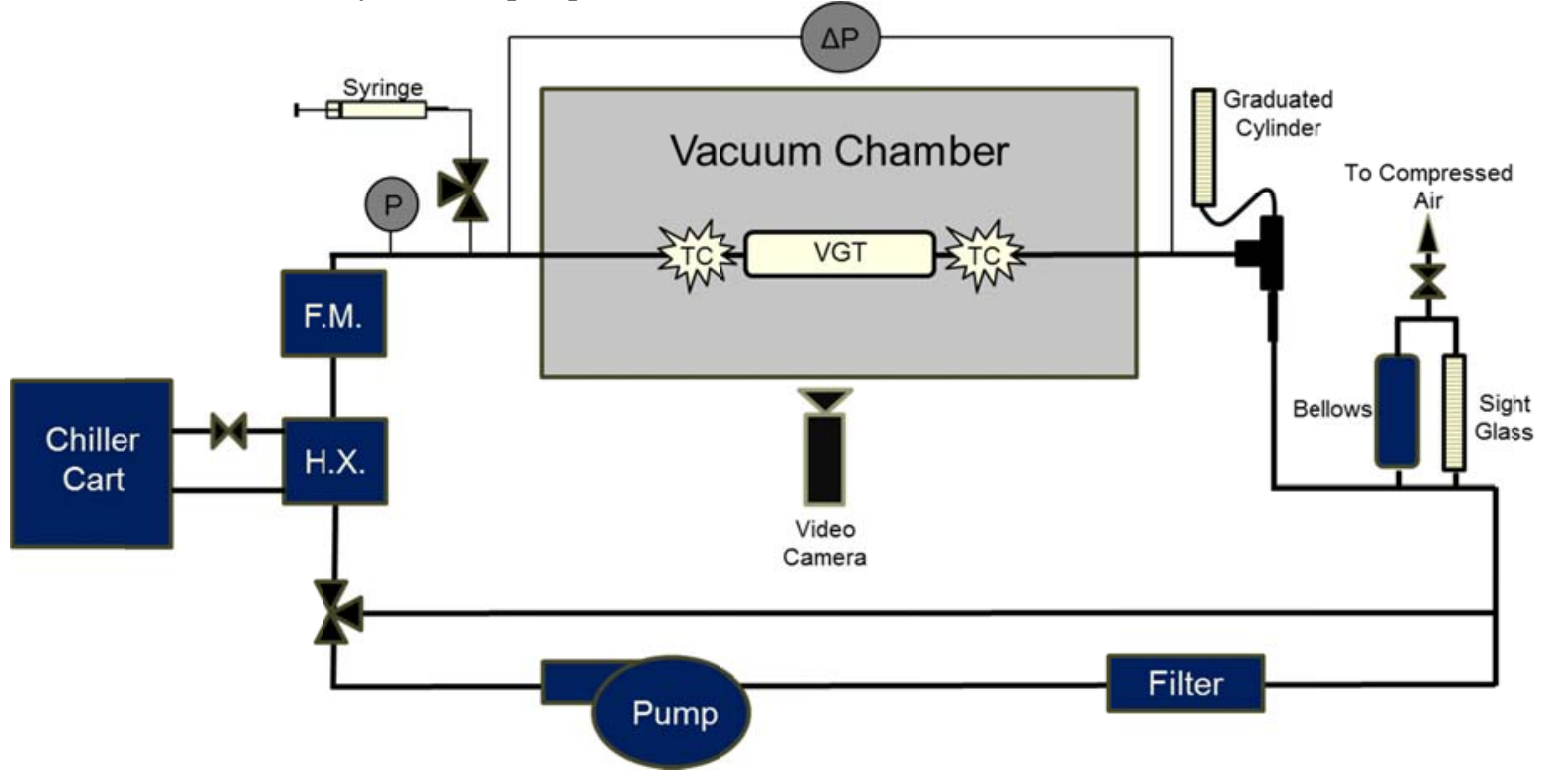

Figure 3. VGT life cycle test schematic. [placeholder figure]

\section{Results}

\section{[Testing is in progress, results TBD]}

\section{Conclusions and Forward Work}

The VGT is a compact, lightweight gas trap that meets all the requirements for the Orion spacecraft. The device is $869 \mathrm{~cm}^{3}\left(53 \mathrm{in}^{3}\right)$ and $0.68 \mathrm{~kg}(1.5 \mathrm{lbm})$ when filled with water, about $34 \%$ and $22 \%$, respectively, of the maximum volume and mass requirement. The overall pressure drop across the VGT is well below the maximum pressure drop. The VGT successfully removed all the free gas from the 77 injections without any gas escaping to the gas collection device. Each injection was vented completely from the VGT with 5 minutes. The water loss due to evaporation from the VGT during 15 days of ambient operation and 6 days of vacuum operation was less than $3 \mathrm{lbm}$.

Long-duration exposure tests are under way to determine whether the VGT is sensitive to leachants from a number of potential LCG tubing materials. The VGT will also be included in vPIST, a series of tests at variable cabin pressures designed to test the integrated MPCV environmental control and life support, active thermal control and suit systems. An ambient PIST was completed in the fall of 2011. The ambient PIST tested MPCV air revitalization hardware with modified ACES suits. The intermediate pressure and vacuum pressure tests are scheduled for the summer of 2013 and the summer of 2014, respectively. These two-person integrated tests will incorporate more development hardware, including the LCG and liquid cooling loop. 


\section{References}

${ }^{1}$ Begley, C., Boehm, P., and Derrickson, S. "LCG Cooling Loop Water Loss, Gas Inclusion and Ops Assumptions" presentation to ECLS/Suit/Cockpit Working Group, June 2011.

${ }^{2}$ Datasheets for Liqui-Cel Membrane Contactors, www.liquicel.com/product-information/data-sheets.cfm.

${ }^{3}$ Weng, D., “Alternate Gas Trap Assembly, Internal Thermal Control System,” Honeywell Verification Report, 12-77650, December 3, 2012.

${ }^{4}$ Bue, G. C., Trevino, L. A, Tsioulos, G., and Hanford, A., "Testing of Commercial Hollow Fiber Membranes for Spacesuit Water Membrane Evaporator,” International Conference on Environmental Systems (ICES), SAE International, 2009.

${ }^{5}$ Vogel M., Vonau W., Trevino L., and Bue G., "Sheet Membrane Spacesuit Water Membrane Evaporator Design and Thermal Tests,” AIAA-2010-6039, 40th International Conference on Environmental Systems, Barcelona, Spain, July 2010.

${ }^{6}$ Bue G.; Trevino L., Tsioulos G., Settles J., Colunga A., Vogel M., and Vonau W., "Hollow Fiber Spacesuit Water Membrane Evaporator Development and Testing for Advanced Spacesuits,” AIAA-2010-6040, 40th International Conference on Environmental Systems, Barcelona, Spain, July, 2010.

${ }^{7}$ Vonau Jr., W., Vogel, M., Conger, B., Hanford, T., Zapata, F. Mitchell, K. Dillon, P., and Frodge, C. "Sheet Membrane and Hollow Fiber Spacesuit Water Membrane Evaporators Test Report,” ESCG-4470-10-TEAN-DOC-0016, Engineering Sciences Contract Group, 2010. 